\title{
Lipogranuloma of bone
}

\author{
G. A. GRESHAM, D. H. MELCHER, AND R. A. J. WHitelAW \\ From the Department of Pathology, University of Cambridge, and Department of \\ Radiology, Addenbrooke's Hospital, Cambridge
}

SYNOPSIS Five cases of lipogranuloma of bone are described. The possible aetiology and nomenclature of the condition are discussed.

Deposits of lipid-laden cells may appear in the skeleton under a variety of circumstances. Sometimes they evoke no reaction in the adjacent tissues and are usually a local manifestation of a generalized lipidosis such as Hand-Schüller-Christian disease. Solitary lesions, which are not part of a generalized disturbance of lipid metabolism, also occur, as in eosinophil granuloma of bone or in lipogranuloma of bone. There is a cellular reaction associated with such lesions.

This paper describes five examples of osseous lipogranuloma, a condition in which necrotic, lipidrich material in the medulla of bone is surrounded by a fibrous capsule rich in cholesterol-laden foreign body giant cells. The patients were seen at Addenbrooke's Hospital, Cambridge, during the years 1951 to 1965 . During that time one example of eosinophil granuloma of bone, three of HandSchüller-Christian disease, and two of Letterer-Siwe disease were seen.

\section{CASE REPORTS}

CASE 1 W.S., a man aged 63, was first seen in 1934 suffering from rheumatoid arthritis, affecting the wrists and hands. This increased in severity involving elbows, shoulders, neck, hips, knees, and ankles; the patient had been bed-ridden since 1940 .

He was admitted to hospital in 1958 with a history of a painless lump in the left tibia for one month. $X$-ray examination revealed cystic swellings in the left tibia and lateral condyle of the femur, which did not communicate with the knee joint. At operation a thick-walled cavity was found containing brown inspissated material, in the antero-medial border of the tibia. A wedge of cortex was removed; following the histological report (vide infra S58/1161) he was given deep $x$-ray therapy to the bone.

While still in hospital the patient fractured the left tibia at the operation site. The fracture united uneventfully but the cystic changes remained.

Received for publication 7 September 1965.
In 1958 an ischaemic ulcer appeared on the left little toe and in 1959 he developed an ulcer on the left third toe which extended on to the sole. He was readmitted in 1961 as the condition of the toes and sole of the foot had got worse and the peripheral circulation was now very poor. A below-knee amputation was done and postoperative recovery was uneventful. Later, in 1961, an ulcer appeared on the second toe of the right foot and shortly afterwards the right leg was removed below the knee. At this time he was found to have diabetes mellitus which was treated with insulin, tolbutamide, and later by diet alone.

In 1962 the left amputation stump discharged yellow material, which was not examined by the laboratory, and an above-knee amputation was done. After the operation he developed a sacral bed-sore which healed slowly but the amputation site continued to discharge; this led to a further shortening of the bone. Eventually the bed-sore and the amputation site healed and he was discharged from hospital. He had since been seen as an out-patient and although he was admitted in February 1963 (with a chest infection) and in July 1963 (with glaucoma), he had no further trouble with the bones; however the cystic changes persisted in those bones in which they were originally seen. A résumé of radiological findings is as follows:-

A destructive arthritis of the rheumatoid type, involving both wrists and elbows, was the first abnormality found in 1950 . Eight years later when the patient presented with a cystic swelling over the upper end of the left tibia a skeletal survey was done. In addition to advanced arthritis of rheumatoid type involving many joints, the most extensive long-bone change was in the upper $19 \mathrm{~cm}$. of the left tibia. The bone was expanded, the cortex was thinned, and the trabeculae were replaced by a 'basket' pattern (Fig. 1); a pathological fracture later occurred here. Similar cystic changes involved the lower ends of both femora, the upper end of the right tibia, and also the left patella (Fig. 2). These lesions were, however, much smaller than that of the left tibia.

Extensive atheromatous calcification was seen in femoral, popliteal, and interdigital arteries on both sides.

In 1962 and 1963 further skeletal surveys were done. The hip joints showed bilateral protrusio acetabuli with partial destruction of the left and complete destruction of 

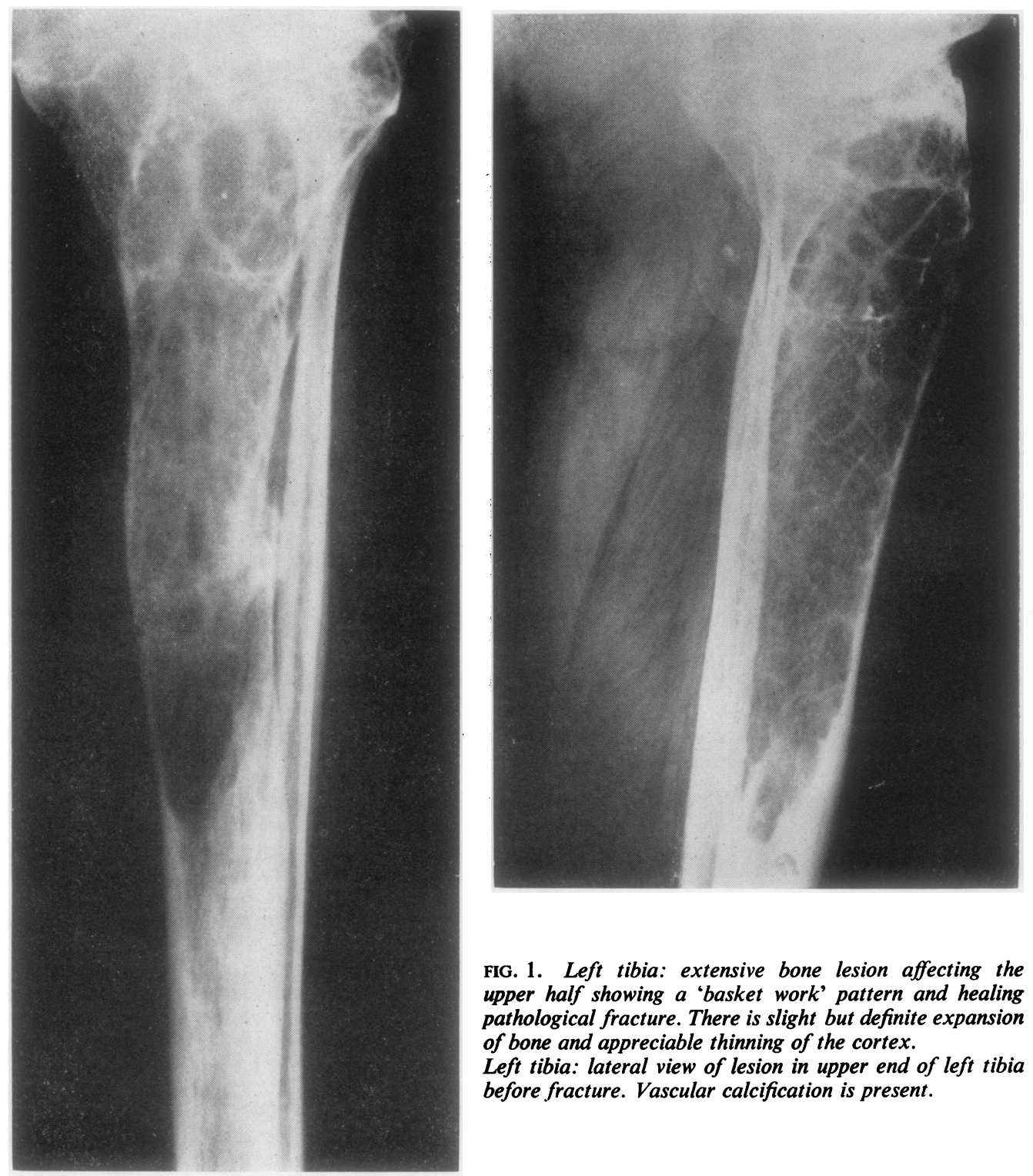

FIG. 1. Left tibia: extensive bone lesion affecting the upper half showing $a$ 'basket work' pattern and healing pathological fracture. There is slight but definite expansion of bone and appreciable thinning of the cortex.

Left tibia: lateral view of lesion in upper end of left tibia before fracture. Vascular calcification is present.

the right femoral head. These changes were thought to be due to a chronic destructive arthritis of the rheumatoid type. Similar advanced changes involved both shoulder joints. At no time was any radiological abnormality noted in the ribs, skull (including the orbits), spine, or chest.

The skeletal appearances were regarded as lipogranuloma of bone together with arthritis of rheumatoid type.

The plasma cholesterol was $302 \mathrm{mg} . / 100 \mathrm{ml}$. (normal range $150-300 \mathrm{mg} . / 100 \mathrm{ml}$.); plasma total lipids 0.61 g./100 ml. (normal range 0.45-1.26 g./100 ml.); acid phosphatase 2.1 Gutman units (normal range 1-44; alkaline phosphatase 2.4 Bodansky units (normal rarge 1.5-4); plasma calcium $10.6 \mathrm{mg}$. $/ 100 \mathrm{ml}$. (normal range $9-11 \mathrm{mg} . / 100 \mathrm{ml}$.); and total plasma protein $7.8 \mathrm{cg}$. (normal range 6.3-8.3). Electrophoresis showed decreased albumin and increased gamma globulin. The E.S.R. wgs $35 \mathrm{~mm}$. in the first hour (Wintrobe); haemoglobin le elel was $11.5 \mathrm{~g}$. $/ 100 \mathrm{ml}$. A blood film showed normochrona and some anisocytosis. A white cell count gave 6,50 per c.mm. (neutrophils $70 \%$, eosinophils $2.0 \%$, lympliocytes $16 \%$, monocytes $12 \%$ ). The Wassermann reaction, Kahn test, and complement-fixation test were negative $A$ 


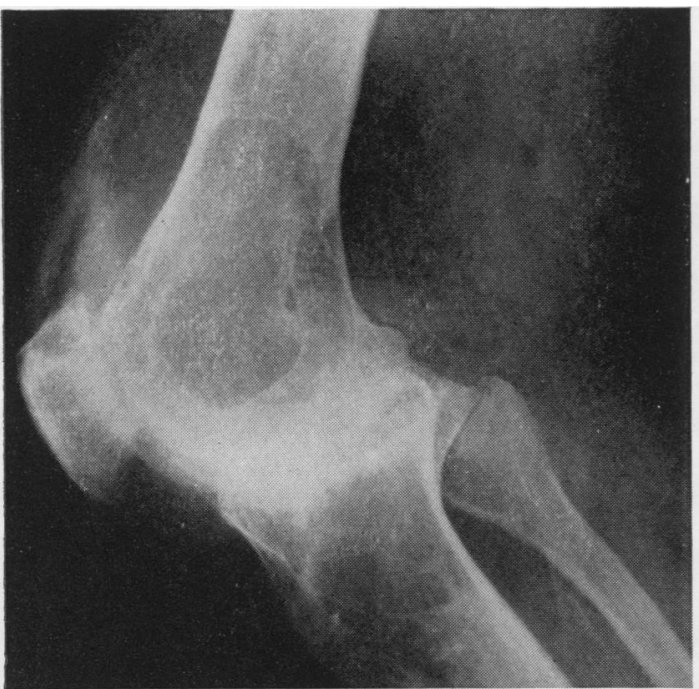

FIG. 2. Right knee: cystic lesion in lower end of right femur and upper end of tibia. Severe thinning of the cortex but no expansion of bone. Knee joint practically ankylosed and also narrowing of patello-femoral joint. These later changes are due to rheumatoid arthritis. Again vascular calcification is shown.

swab from the operation site was sterile. Mycobacterium tuberculosis was not grown.

Morbid anatomy (S58/1161) A biopsy of the cyst in the upper left tibia showed a wall of fibro-fatty tissue containing groups of chronic inflammatory cells (lymphocytes, histiocytes, and occasional plasma cells), amorphous debris, cholesterol clefts, and spicules of calcium. A wedge of adjacent tibial cortex showed moderately vascular, dense connective tissue mingled with lipid-filled cells, cholesterol clefts, and occasional giant cells of foreign body type.

A biopsy, taken at the same time from the tibialis anterior muscle, showed conspicuous sarcolemmal nuclei and areas of granulation tissue in which there were small groups of lymphocytes. In the left, below-knee, amputation specimen (S61/5560) there was a cyst $(1.5 \mathrm{~cm}$. diam.) in the posterior part of the tibia near the ankle joint, containing glistening yellow material surrounded by thin bone. The cyst did not extend to the proximal cut surface of the bone.

Histological examination of the cyst showed a wall of fibrous tissue in which were abundant lipid-filled cells, foreign body giant cells, and some haemosiderin deposits. The posterior tibial artery contained canalized thrombus. In the left, above-knee, amputation specimen (S62/1609) there was a cyst in the upper end of the left tibia lined by purple-grey tissue (Fig. 3). Superiorly it opened into the knee joint (Fig. 4) and inferiorly on to the skin surface through an ulcer $3 \mathrm{~cm}$. proximal to the amputation scar.

Histological examination showed a cyst lined by dense connective tissue in which were numerous haemosiderin
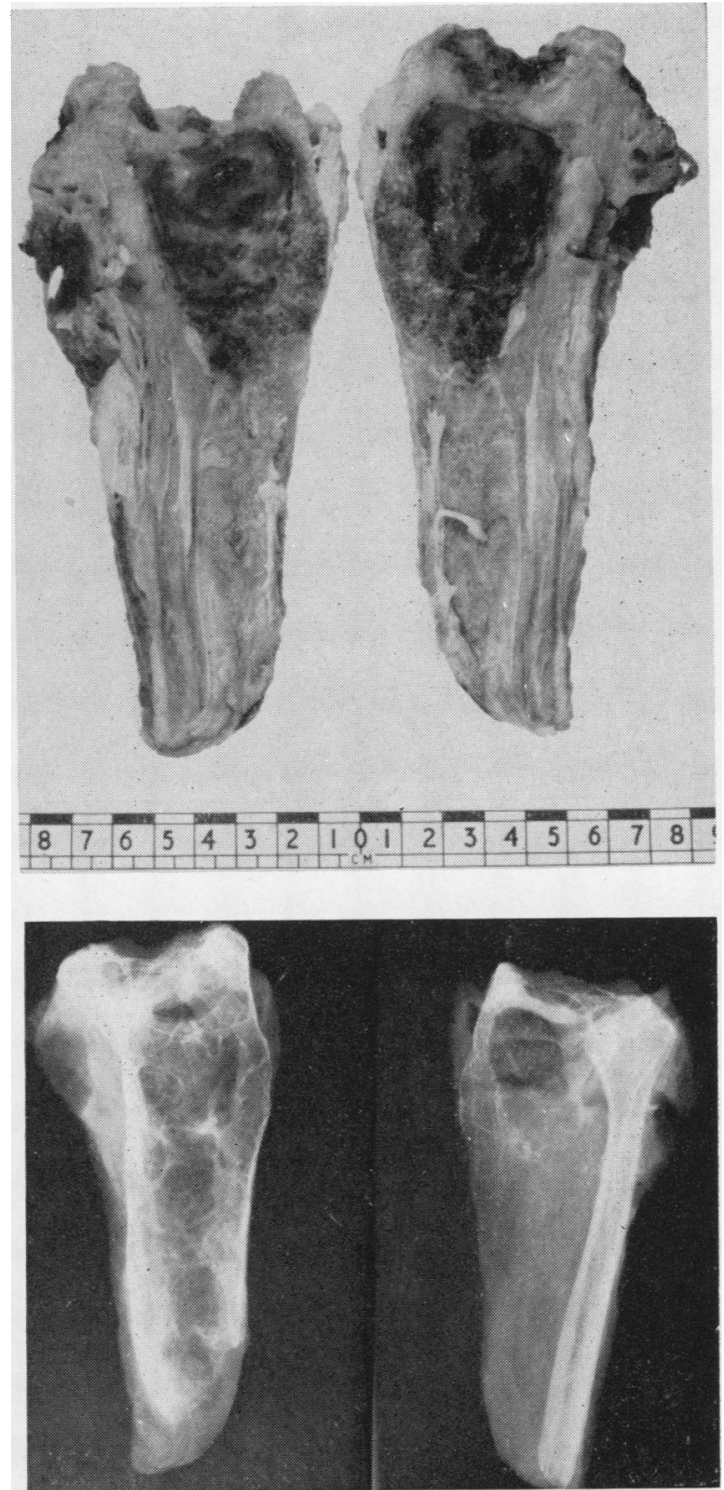

FIG. 3. Tibia split in half to show cyst and radiograph of the specimen (S62/1609).

deposits and cholesterol clefts. Collections of chronic inflammatory cells (plasma cells, histiocytes, lymphocytes, and occasional eosinophil leucocytes) surrounded blood vessels in the connective tissue (Fig. 5).

A section of the popliteal artery showed atherosclerotic narrowing of the lumen.

His final admission to hospital was in March 1965; he had haematemesis and pain in the right hypochondrium for two days. He had been taking aspirin to relieve the pain. The diabetes was controlled without insulin. He became 


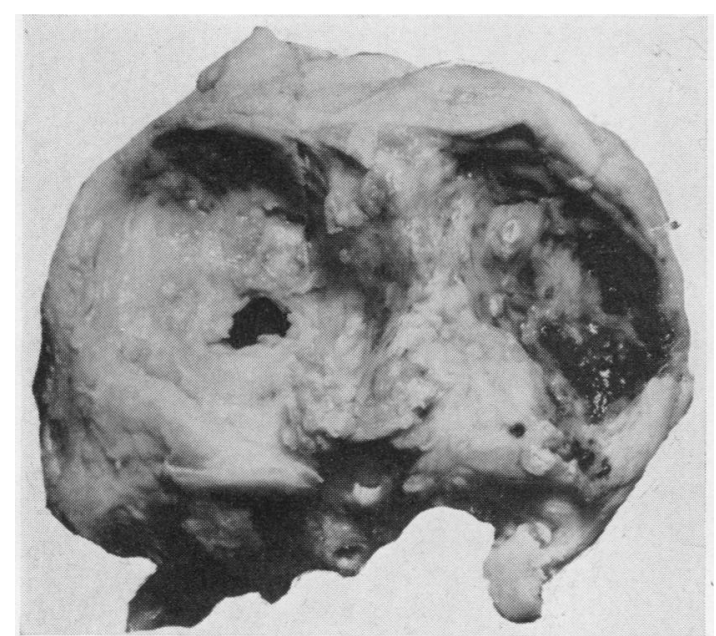

FIG. 4. Superior aspect of tibia showing hole into knee joint (S62/1609).

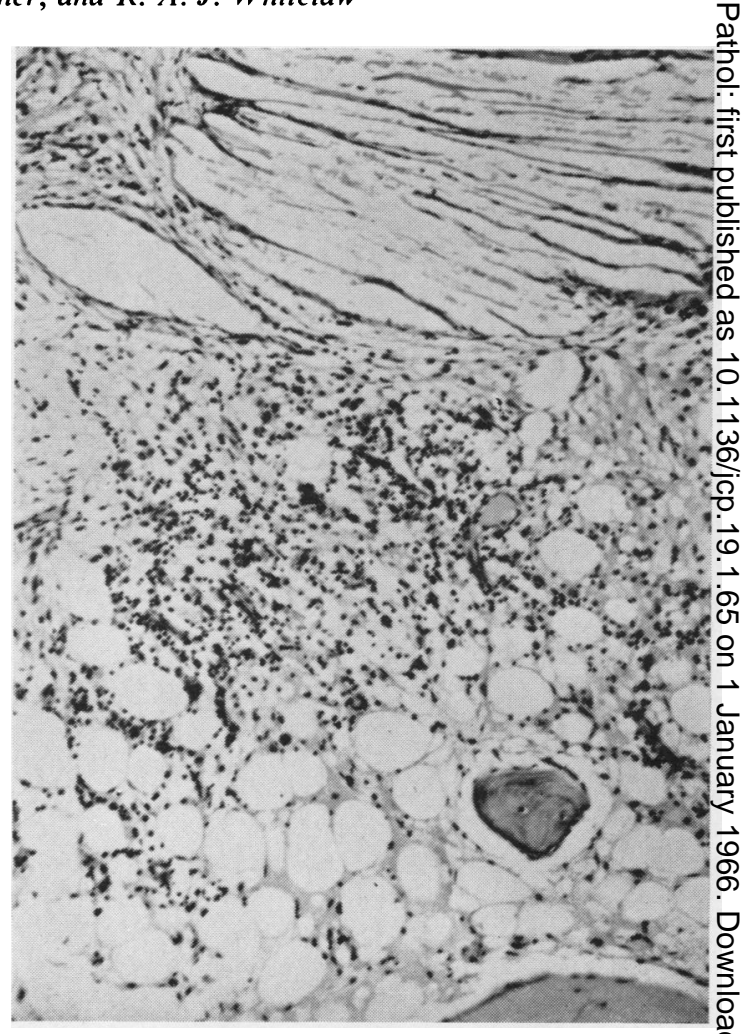

FIG. 5. Part of the cyst wall (S62/1609) showing chole- $\frac{\mathbb{Q}}{\mathrm{D}}$ sterol clefts, collagen, and clumps of chronic inflammatory cells. (Haematoxylin and eosin $\times 150$.)

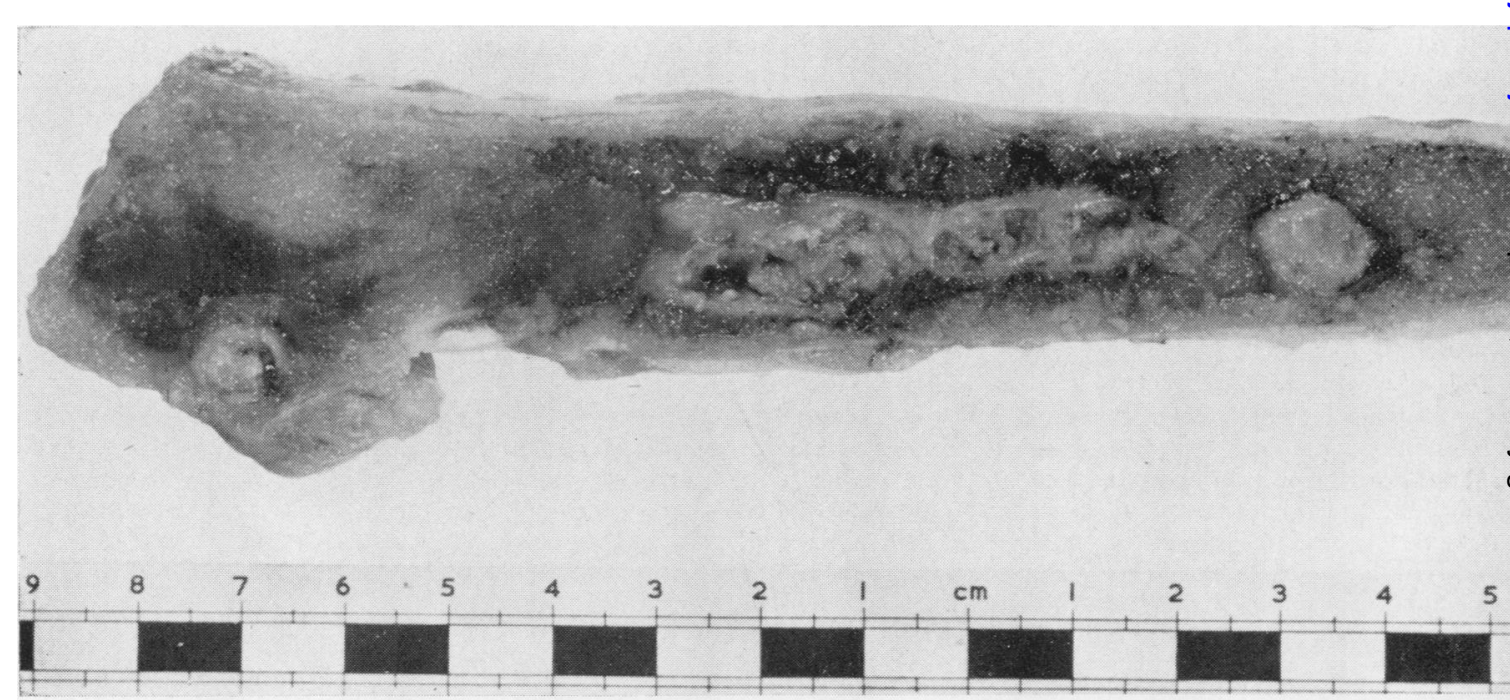

FIG. 6. Upper end of right humerus showing loss of head and cysts (P65/182). 


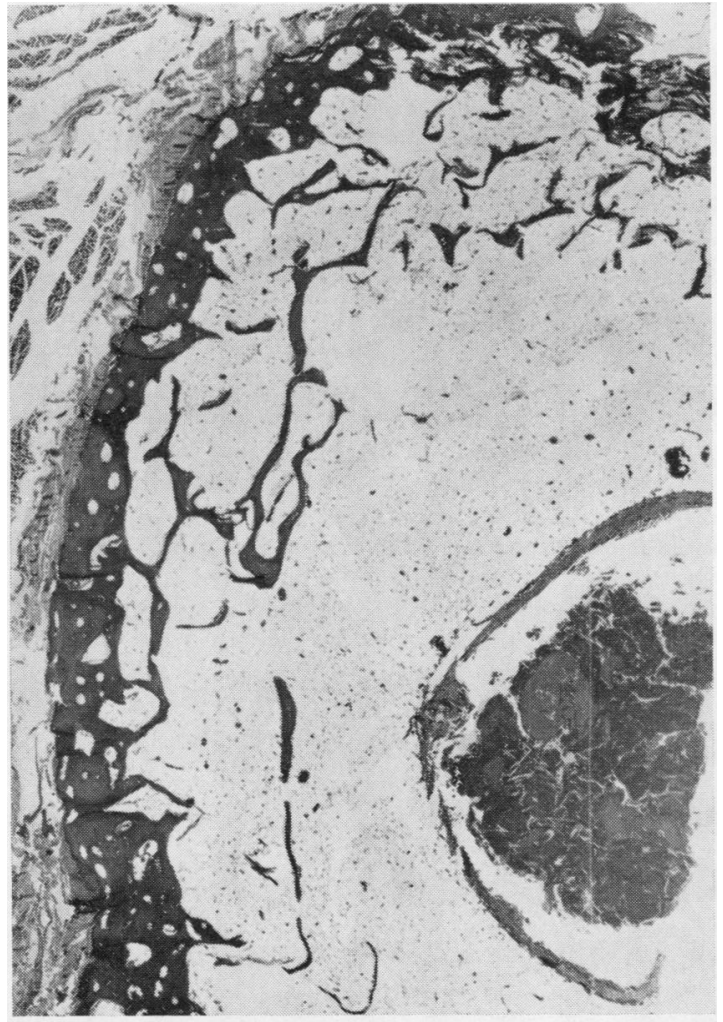

FIG. 7.

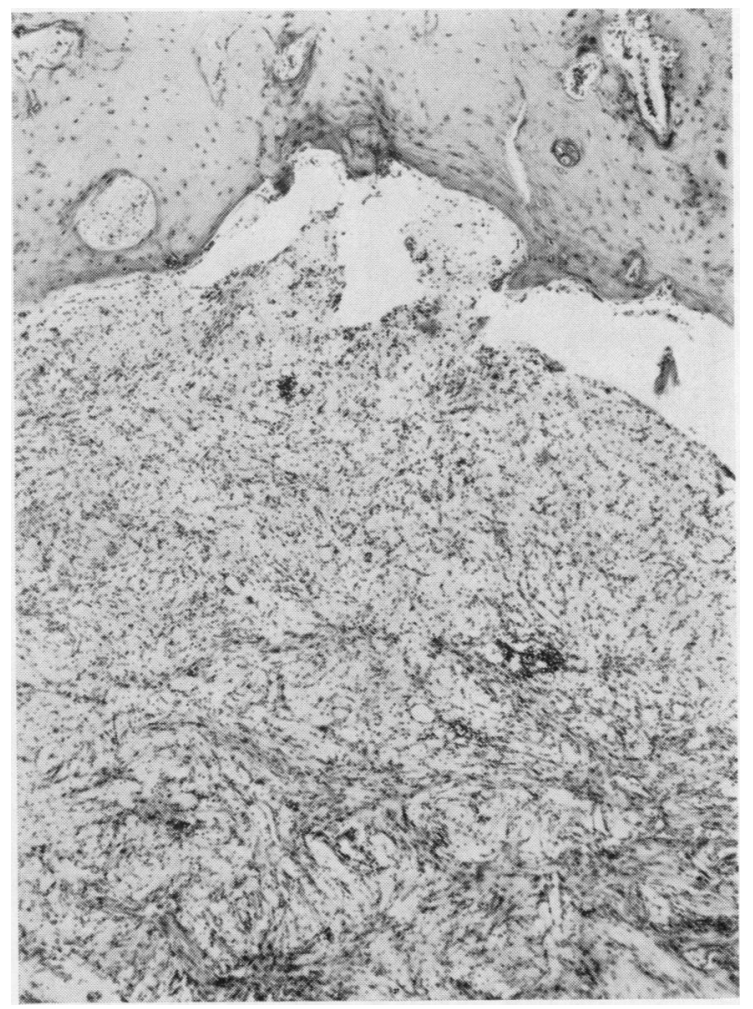

FIG. 8.

FIG. 7. T.S. of right humeral cyst. (Haematoxylin and eosin $\times 6 \cdot 5$.) $($ P65/182).

FIG. 8. A mass of lipid-laden cells bordered by lamellar bone (case 2). (Haematoxylin and eosin $\times 40$.) (S61/1172).

febrile $\left(101 \cdot 5^{\circ} \mathrm{F}\right.$.) on the day after admission and died suddenly.

Necropsy (P65/182) was done 36 hours after death. He was a plump, pale, bald, old man; the amputation stumps, in the legs, were well healed. Both wrists and hands showed considerable rheumatoid deformity. The fingers were thin, covered with tight, white skin and there was much hyperextension of the interphalangeal joints; the wrists were greatly swollen and excessively mobile. Both elbow and shoulder joints contained each as much as $50 \mathrm{ml}$. of creamy yellow material in which were a few more firm lumps. The heads of both humeri had vanished (Fig. 6) and there were three cysts in the shaft of the right humerus which were filled with semi-solid yellow material (Fig. 7). A similar large cyst in the lower end of the right femur connected with the knee joint through a hole $(0.3 \mathrm{~cm}$. diameter) on the inferior articular surface of the lateral condyle. The piece of tibia that remained had a similar cyst in the marrow cavity which communicated with the joint by a hole $(0.5 \mathrm{~cm}$. diameter $)$ in the superior tibial surface. The heads of both femora had largely disappeared. No cysts were found in pelvis, ribs, skull, sternum, or vertebrae.

There was severe aortic atherosclerosis with narrowing and recent thrombosis at the origin of the right femoral artery. The heart was not remarkable, there was only moderate coronary atherosclerosis. Areas of recent bronchopneumonia were seen in the lower lobes of both lungs. Other organs were not remarkable.

Coliform bacilli were grown from the material in the right shoulder joint. A chemical analysis of material from the elbow joints and femoral cyst revealed $50 \%$ to be lipid, most of which was cholesterol or cholesterol ester esterified with mainly oleic and linoleic acids. An analysis of normal perirenal fat showed, as was expected, predominantly triglyceride rich in palmitic and oleic acids. Histological examination of joint synovium confirmed the diagnosis of rheumatoid disease. The cysts were similar in appearance to those previously examined by biopsy.

CASE 2 A.W., a man aged 52, was first seen in March 1961 complaining of an aching pain on the outer side of the left knee and a feeling of 'giving way' for 18 months. Radiology showed a cystic trabeculate lesion in the lateral condyle of the left femur which was thought to be an 'osteoclastoma'. A skeletal survey was otherwise normal. 


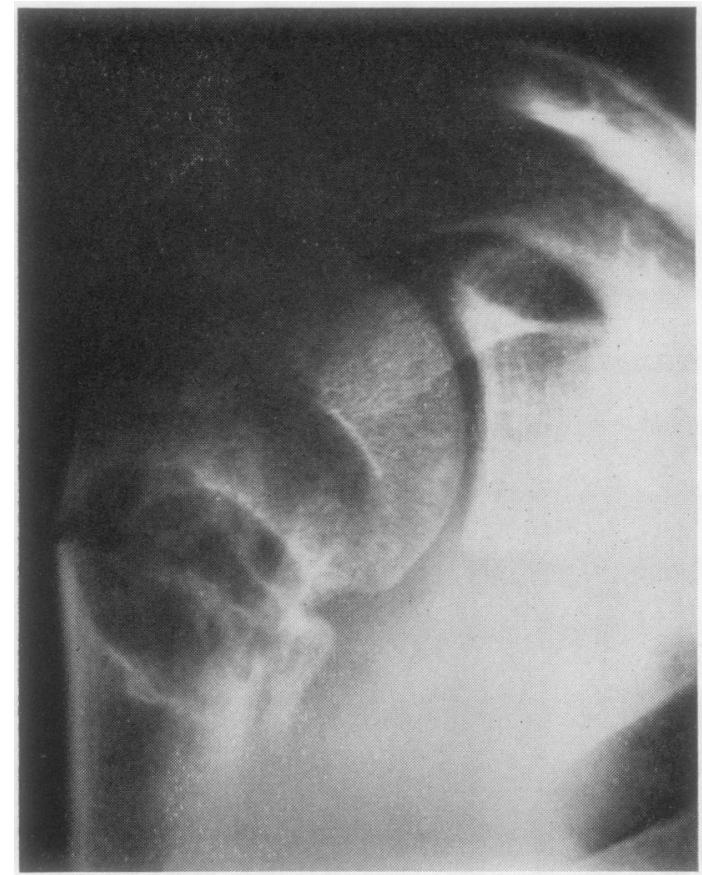

FIG. 9. Right humerus: well-defined cystic lesion with sclerotic margin. A pathological fracture is present.

Serum cholesterol was $228 \mathrm{mg}$. $/ 100 \mathrm{ml}$. Latex fixation and Rose Waaler tests were negative. Haemoglobin was $13.3 \mathrm{~g} . / 100 \mathrm{ml}$., and a blood film showed normochromia and normocytosis. The W.B.C.s numbered 7,500/c.mm. (neutrophils $60 \%$, eosinophils $3 \%$, monocytes $8 \%$, basophils $1 \%$, lymphocytes $19 \%$ ). The E.S.R. was $7 \mathrm{~mm}$. in the first hour (Wintrobe).

The cyst was explored surgically and was found to be filled with soft yellowish-brown, semi-solid material; the contents were curetted and the cavity packed with cancellous bone. The post-operative course was uneventful and the patient was discharged two weeks later. He was last seen in February 1963 when he had a full range of movement of the knee joint and radiographs showed complete sclerosis of the cavity.

Histological examination (S61/1172) showed lipidfilled cells enmeshed in dense and loose connective tissue together with numerous cholesterol clefts (Fig. 8). Scattered in the connective tissue and occasionally among the lipid-filled cells were collections of histiocytes, lymphocytes, occasional plasma cells, and haemosiderin.

CASE 3 E.T., a man aged 18, in March 1961 fell and broke his right humerus while playing football. Radiology showed a fracture through a cystic swelling in the upper end of the right humerus (Fig. 9). A skeletal survey was otherwise normal. The fracture was treated conservatively and united clinically although the cyst remained. He was admitted in May 1962 for exploration and biopsy.

Serum cholesterol was $214 \mathrm{mg}$. $/ 100 \mathrm{ml}$.; serum calcium $10 \cdot 2 \mathrm{mg} . / 100 \mathrm{ml}$. (normal range 9-11); serum inorganic phosphate $3.4 \mathrm{mg} . / 100 \mathrm{ml}$. (normal range $2.5-4 \overline{\bar{\sigma}}$; alkaline phosphatase 3.5 K.A. units (normal range 4:59.5); acid phosphatase 1.6 K.A. units (normal raق̆ge 1.2-3.1); tartrate labile 0.2 (normal range $0-0.7$ f $^{2}$; serum total protein $7 \cdot 0 \mathrm{~g}$. (normal range 6:3-8.3). Elec Fophoresis was normal. Haemoglobin was $14.8 \mathrm{~g}$./100 $\mathrm{m}$. and W.B.C.s numbered $8,300 \mathrm{c.mm}$. (neutrophils $77 \%$, eosinophils $1 \%$, lymphocytes $19 \%$, monocytes $3 \%$ ). the E.S.R. was $3 \mathrm{~mm}$. in the first hour (Wintrobe).

At operation a cavity was found filled with yellowbrown semi-solid material, which was removed and The cavity packed with cancellous bone chips. He was seen regularly as an outpatient and was discharged in Mash 1962 when he had a full range of arm movements and $x$-ray film showed that the cavity had almost entirely gofne.

Histological examination (S61/2024) showed lipid-filled cells embedded in loose and occasionally very vascular and dense connective tissue in which were numerons cholesterol clefts and abundant deposits of haemosideegin. Occasional collections of lymphocytes and histiocytes were seen around blood vessels (Fig. 10).

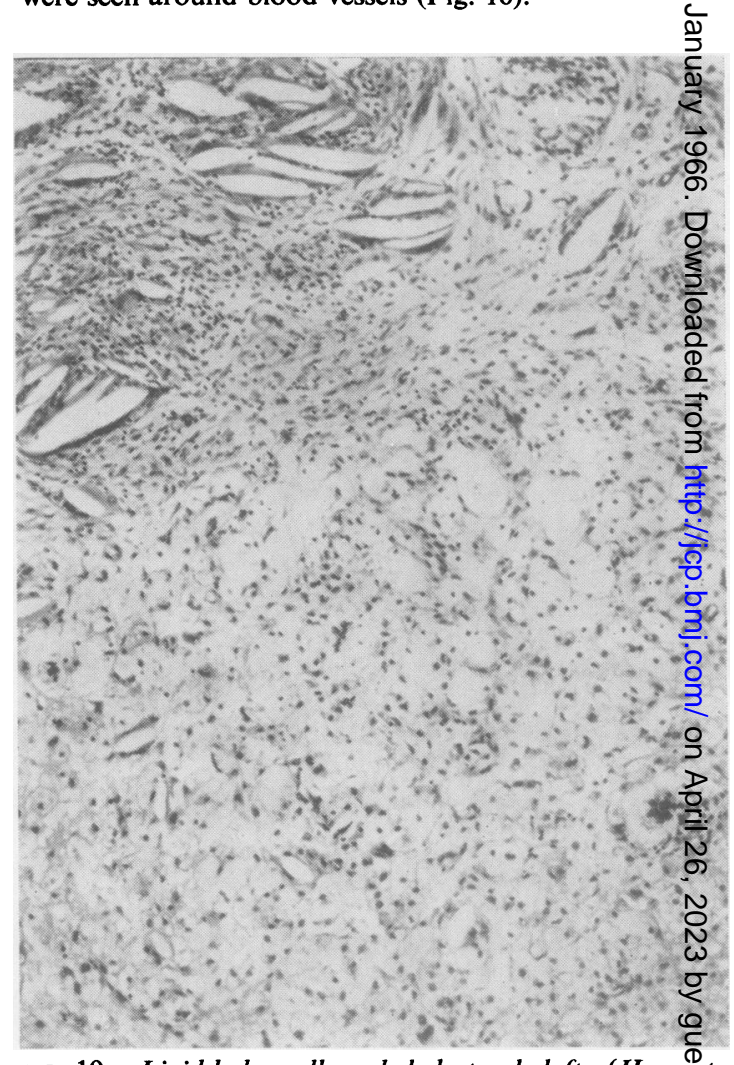

FIG. 10. Lipid-laden cells and cholesterol clefts. (Haematoxylin and eosin $\times 100$. $)($ S61/2024).

CASE 4 A.K., a woman aged 69, was first seen in 19 1. She had wrenched her left knee two years before andiin July 1950 noticed a small lump at the left knee which had increased in size and had recently become painfux 
A 'swelling' was excised from the lower end of the femur in July 1951 and was thought to be a fibrosarcoma at the time. No other investigations were made nor has she been seen subsequently at this hospital.

Histological examination (S51/2285) showed dense vascular connective tissue containing a moderate number of lipid-filled cells and groups of histiocytes, lymphocytes, and occasional plasma cells around blood vessels. A number of giant cells were present, some suggestive of tuberculosis, but there was no evidence of caseation and a search for acid-alcohol-fast bacilli was unsuccessful.

CASE 5 T.H., a man aged 21, was serving in the U.S.A.F. and was stationed in Cambridge. He had suffered pain in the knee since 1954 and in 1958 a cystic lesion was found in the upper end of the tibia on $x$-ray examination; this lesion was curetted.

No follow-up history or past medical records have been obtained as the patient has returned to the U.S.A.

Histological examination (S58/0564) showed lipidfilled cells enmeshed in loose connective tissue; numerous haemosiderin deposits were present. Occasional collections of histiocytes and a few plasma cells were seen around the scanty blood vessels.

\section{DISCUSSION}

Lipogranuloma of bone is one of the many conditions where cystic areas may be found in the skeleton. The lesions in this disorder are usually in long bones. The lesion is characteristic, consisting of a core of amorphous lipid-rich material and abundant lipid-laden cells bordered by a fibrous capsule which encloses cholesterol clefts and giant cells. Small, presumably early, lesions are sharply demarcated from the apparently normal adipose marrow in which they occur. As the lesion gets bigger it perforates the articular cartilage if it lies at the bone ends and the joint fills with pultaceous debris. The cortex of bones containing the lesions seems to resist perforation. The overall appearances suggest an inflammatory reaction to necrotic adipose tissue rather than a neoplastic process. The initial cause of the tissue necrosis is not, however, clear.

The condition has some similarities to HandSchüller-Christian disease, reticuloendotheliosis (Letterer-Siwe disease), and eosinophil granuloma (Lichtenstein and Jaffe, 1940) or solitary granuloma of bone (Otani and Erlich, 1940). Jaffe and Lichtenstein (1944) consider all these conditions as different clinico-anatomical expressions of a common basic disorder and other authors support this view (Snapper, 1949; Mallory, 1942; Farber, 1941).

In Hand-Schüller-Christian disease the common sites of lesions are the skull and pituitary fossa and the lesions often cause exophthalmos, diabetes insipidus, and infantilism. About one third of the cases of Hand-Schüller-Christian disease end fatally
(Snapper, 1949), as lesions may involve the brain, lungs, and heart. Hand-Schüller-Christian disease is not a primary disorder of lipid metabolism and hypercholesterolaemia occurs only rarely (Snapper, 1949). The true cholesterol analogue (Jaffe and Lichtenstein, 1944) to Gaucher's disease and Niemann-Pick disease is xanthoma tuberosum multiplex which must be distinguished from lipogranulomas of bone.

Reticuloendotheliosis (Letterer-Siwe disease) rarely occurs over the age of 4 (Mallory, 1942) but an adult form is recognized and is always fatal (Snapper, 1949). This rare disease shows fever, generalized lymphadenopathy, enlarged liver and spleen, purpura, anaemia, osteolytic areas in bone, and proliferation of reticulo-endothelial cells.

Solitary or eosinophil granuloma of bone is a cystic lesion in which eosinophil leucocytes are conspicuous; however, lesions may be multiple (Green and Farber, 1942). Jaffe and Lichtenstein (1944) state that, in eosinophil granuloma, the lesions do not tend to become scarified, 'collagenized' and 'lipidized', whereas to justify the diagnosis of lipogranuloma the disease should show at least some lesions which have already become 'scarified, collagenized, and lipidized'. Farber (1941) had earlier maintained that eosinophil granuloma is converted into a lipogranuloma, but Jaffe (1958) has again emphasized that spontaneous healing of an eosinophil granuloma is by resolution and not by conversion to a lipogranuloma.

Radiologically any well-circumscribed, cyst-like lesion in bone may be due to lipogranuloma. These may be single or multiple and can occur at any age.

Lesions of lipogranuloma tend, however, to have certain characteristics: the translucencies are oval rather than circular and in the long bones the long axis is parallel to the shaft. The lesion may have a basket-like pattern as occurred in the patient W.S. described here.

The lesion usually arises deep in the cancellous bone and is always well demarcated. It may be surrounded by a white line of sclerotic bone though this is unusual. Some lesions remain at about a centimetre in size. Others, however, enlarge considerably further than this, particularly in the major long bones or in the vault of the skull. The lesions may expand enough to reach the cortex witch then becomes thinned but is rarely expanded over it. Spontaneous fractures may occur causing secondary subperiosteal callus. Common sites of the lesions are the submetaphyseal areas of the middle third of the femora and tibia, the ischial pubic rami, the humeri, the middle third of the ribs, and the vault of the skull. Thus when a cyst-like translucency is seen and the diagnosis is not obvious a skeletal survey 
to exclude other bone lesions giving superficially similar lesions, e.g., osteoclastoma, fibrous dysplasia, osteogenic fibroma, and hyperparathyroidism, should be made. This should include lateral skull radiographs and antero-posterior radiographs of the pelvis, femora, and humeri. A radiograph of the chest may also be of value, as in some patients with lipogranuloma reticular or nodular shadows occur in the lower half of the lung fields.

Xanthomatous deposits in soft tissues, adjacent to joints, with secondary erosion of bone were described by Weber in 1943. In 1953 Golden and Richards described two cases with rheumatoid polyarthritis and advanced cystic changes in long bones. Histologically they were 'xanthogranulomatous' lesions and in one of them the cystic swellings in the soft tissues showed a similar histological appearance to the cysts in the bones.

In our cases four of the five patients had a solitary lesion and apparently made an uneventful recovery. The fifth (W.S.) had multiple lesions, associated diabetes mellitus, peripheral vascular disease, and rheumatoid arthritis.

It has been suggested that trauma might be the initiating cause of lipogranuloma of bone (Otani and Erlich, 1940). In only one of our cases (case 4) was there any history of trauma and yet deposits of haemosiderin were present in all five. This tends to suggest traumatic bleeding, but in cases of 'traumatic' sclerosing lipogranuloma of sucbutaneous tissue (Smetana and Bernhard, 1950), haemosiderin deposits were absent in all but one.

Another possible factor is anoxia. This could well be the cause of case 1 who had severe peripheral vascular disease but there was no evidence of an anoxic factor in the other cases; one (case 3) was a young male of 19 .

It is unlikely that diabetes mellitus played any part in the aetiology of lipogranulomatosis in case 1 except that it may have a predisposed to peripher嗃 vascular disease. Diabetes is a common condition, lipogranuloma of bone is rare.

In case 1 lipogranulomatosis was first discoveref 24 years after the patient developed severe art progressive rheumatoid arthritis, and Golden ane Richards (1953) describe an association of rheumato arthritis with lipogranuloma of bone. However, none of the other four patients in our series hafet rheumatoid arthritis.

In 1953 Lichtenstein in a review of the literature suggested to name 'histiocytosis $\mathrm{x}$ ' for the group diseases to include Letterer-Siwe disease, Han Schüller-Christian disease, and eosinophil gran loma. It seems likely that lipogranuloma of bone 48 another facet of this spectrum of disorder. The ter $\vec{m}$ lipogranuloma is as adequate as any. It emphasizes the probable inflammatory nature of the conditio and the presence of lipids. The suffix 'oma' likewise points out that the lesion often appears as a swelling Finally the term does not suggest a cause.

Thanks are due to S. W. Patman and L. F. H. Beard for the photographs, Miss B. D. Disbrey for the histologic preparations, Miss J. E. Claydon for secretari\$ assistance, and Mr. D. Jones for the lipid analysis.

\section{REFERENCES}

Farber, S. (1941). Amer. J. Path., 17, 625.

Golden, G. N., and Richards, H. G. H. (1953). J. Bone Jt Surg., 35B 275.

Green, W. T., and Farber, S. (1942). Ibid., 24, 499.

Jaffe, H. L. (1958). Tumors and Tumorous Conditions of the Bones an Joints. Kimpton, London.

- and Lichtenstein, L. (1944). Arch. Path., 37, 99.

Lichtenstein, L. (1953). Arch. Path., 56, 84.

— and Jaffe, H. L. (1940). Amer. J. Path., 16, 595.

Mallory, T. B. (1942). New Engl. J. Med., 227, 955.

Otani, S., and Ehrlich, J. C. (1940). Amer. J. Path., 16, 479.

Smetana, H. F., and Bernhard, W. (1950). Arch. Path., 50, 296

Snapper, I. (1949). Medical Clinics on Bone Diseases, 2nd e Interscience, New York.

Weber, F. P. (1943). Brit. J. Derm., 55, 1. 